\title{
Micro-shear bond strength and surface micromorphology of a feldspathic ceramic treated with different cleaning methods after hydrofluoric acid etching
}

\author{
Henrique Caballero STEINHAUSER ${ }^{1}$, Cecília Pedroso TURSSI ${ }^{2}$, Fabiana Mantovani Gomes FRANÇA ${ }^{2}$, Flávia Lucisano \\ Botelho do AMARAL ${ }^{2}$, Roberta Tarkany BASTING ${ }^{2}$
}

\author{
1- Imperatriz School of Dentistry, Imperatriz, MA, Brazil. \\ 2- School of Dentistry, São Leopoldo Mandic Dental Research Institute, Campinas, SP, Brazil.
}

Corresponding address: Profa. Dra. Roberta Tarkany Basting - Faculdade de Odontologia e Instituto de Pesquisas São Leopoldo Mandic - Departamento de Odontologia Restauradora - Dentística - Rua José Rocha Junqueira, 13 - Bairro Swift, Campinas-SP - 13045-755 - Brasil - Phone/Fax: 55-19-3211-3600 - e-mail: rbasting@yahoo.com

Submitted: May 12, 2013 - Modification: August 21, 2013 - Accepted: September 20, 2013

\section{ABSTRACT}

\begin{abstract}
bjective: The aim of this study was to evaluate the effect of feldspathic ceramic surface cleaning on micro-shear bond strength and ceramic surface morphology. Material and Methods: Forty discs of feldspathic ceramic were prepared and etched with $10 \%$ hydrofluoric acid for 2 minutes. The discs were randomly distributed into five groups $(n=8)$ : C: no treatment, S: water spray + air drying for 1 minute, US: immersion in ultrasonic bath for 5 minutes, F: etching with $37 \%$ phosphoric acid for 1 minute, followed by 1 -minute rinse, F+US: etching with $37 \%$ phosphoric acid for 1 minute, 1 -minute rinse and ultrasonic bath for 5 minutes. Composite cylinders were bonded to the discs following application of silane and hydrophobic adhesive for micro-shear bond strength testing in a universal testing machine at $0.5 \mathrm{~mm} / \mathrm{min}$ crosshead speed until failure. Stereomicroscopy was used to classify failure type. Surface micromorphology of each treatment type was evaluated by scanning electron microscopy at 500 and 2,500 times magnification. Results: One-way ANOVA test showed no significant difference between treatments $(p=0.3197)$ and the most common failure types were cohesive resin cohesion followed by adhesive failure. Micro-shear bond strength of the feldspathic ceramic substrate to the adhesive system was not influenced by the different surface cleaning techniques. Absence of or less residue was observed after etching with hydrofluoric acid for the groups US and F+US. Conclusions: Combining ceramic cleaning techniques with hydrofluoric acid etching did not affect ceramic bond strength, whereas, when cleaning was associated with ultrasound, less residue was observed.
\end{abstract}

Keywords: Ceramics. Hydrofluoric acid. Scanning electron microscopy.

\section{INTRODUCTION}

The longevity of a ceramic restoration appears to be linked to its physical and mechanical properties, as well as reliable bonding between the restoration and the tooth 25 .

In order to obtain effective bonding between feldspathic ceramics and the tooth substrate, surface treatment is necessary for both the internal aspect of the ceramic and the tooth structure. The use of methods to pretreat the ceramic surface, such as mechanical (burs and aluminum oxide sandblasting), chemical (2.5-10\% hydrofluoric acid etch and silane) or a combination of both (silicon oxide sandblasting) optimize adhesion between the ceramic and the resin cement ${ }^{6,17}$.

The combination of hydrofluoric acid and silane on the internal surface of the ceramic has been the most recommended method to increase bond strength between the ceramic and the tooth substrate when using resin cements ${ }^{9,18}$. However, it has been demonstrated that following hydrofluoric 
acid removal from the ceramic surface, considerable amounts of deposits are formed, which can affect bond strength ${ }^{13}$.

Some studies have proposed cleaning techniques for ceramic surface aiming at removing the residues left by hydrofluoric acid etching, including the use of ultrasonic bath $3,6,15,17,24,37 \%$ phosphoric acid smear $^{19}$, rinsing under running water ${ }^{12,14,23}$ or a combination of $37 \%$ phosphoric acid smear and ultrasonic bath ${ }^{13}$.

Considering the lack of an established protocol to remove residues created by hydrofluoric acid etching of the ceramic surface, the aims of this study were to evaluate: a) the micro-shear bond strength and failure mode between the feldspathic ceramic and the adhesive system following pretreatment of the ceramic surface with different cleaning methods to remove particles generated by hydrofluoric acid etching; b) the feldspathic ceramic surface micromorphology after using different cleaning methods to remove hydrofluoric acid etching residues by scanning electron microscopy (SEM).

\section{MATERIAL AND METHODS}

Forty six feldspathic ceramic discs (Super Porcelain EX-3, Noritake Kizai Co., Ltd, Nishi-Ku, Nagoya, Japan, batch 011906, shade A3,5B) were made, 6 of which were used to assess micromorphology and 40 were used for micro-shear bond strength testing.

The ceramic discs were obtained from $12.5 \mathrm{~mm}$ diameter by $3.6 \mathrm{~mm}$ thick wax patterns using lost wax casting, which gave room to the feldspathic ceramic. The ceramic powder/liquid ratio was used as instructed by the manufacturer and the mixture was placed into the plaster mold using a specific brush provided in the ceramic kit. The investment plaster and ceramic set were placed in a furnace for sintering at the temperature specified by the manufacturer. As the ceramic shrinks by approximately $20 \%$ during sintering, the final disc dimensions were close to $10 \mathrm{~mm}$ in diameter and $3 \mathrm{~mm}$ thick.

\section{Micro-shear bond strength test}

Forty ceramic discs were included in PVC cylinders using polyester resin (Hobby Automotivo, $3 \mathrm{M}$ do Brasil, Sumaré, SP, Brazil). The surfaces of the ceramic discs were sequentially polished using silicium carbide sandpaper (Lixa d'água, 3M, Sumaré, SP, Brazil) of grades 400, 600 and 12005, mounted on a running water-cooled electric polisher (Aropol 2V, Arotec S/A, São Paulo, SP, Brazil). The discs were randomly divided into 5 experimental groups of 8 discs $(n=8)$.

The surface of all ceramic discs was treated with
$10 \%$ hydrofluoric acid (Villevie, Joinville, Santa Catarina, Brazil) for 2 minutes, followed by water and water spray rinse for 30 seconds. Then, the discs were treated according to the experimental groups as follows:

Group C: no additional surface treatment;

Group S: water spray + air for 1 minute, using the 3-in-1 syringe;

Group US: ultrasonic bath (USC1400, Unique Ind. e Com de Prod Elet. Ltda, São Paulo, SP, Brazil) with distilled water for 5 minutes;

Group F: 37\% phosphoric acid smear (Acid Gel, Villevie, Joinville, SC, Brazil), using a disposable brush (Disposable Micro-applicators, Microbrush, Rio de Janeiro, RJ, Brazil) for 1 minute, followed by rinsing under running water for 1 minute;

Group F+US: $37 \%$ phosphoric acid smear (Acid Gel, Villevie, Joinville, SC, Brazil), using a disposable brush (Disposable Micro-applicators, Microbrush, Rio de Janeiro, RJ, Brazil) for 1 minute, followed by rinsing under running water for 1 minute, combined with ultrasonic bath (USC1400, Unique Ind e Com de Prod Elet. Ltda, São Paulo, SP, Brazil) with distilled water for 5 minutes.

Five $0.8 \mathrm{~mm}$ diameter $\times 4 \mathrm{~mm}$ high composite resin (Filtek Z100, 3M ESPE, St. Paul, MN, USA) cylinders were made for each ceramic disc. Therefore, a layer of silane (Dentsply, Petrópolis, RJ, Brazil) was previously applied to bond the resin onto the ceramic. A layer of adhesive (Adper Scotchbond - Adhesive, 3M ESPE, St. Paul, MN, USA) was applied and light-cured using halogen light (Demetron, LC Kerr Corporation, Orange, CA, USA) for 10 seconds. Then, silicone tubes $4 \mathrm{~mm}$ high $\times 0.8 \mathrm{~mm}$ diameter were placed on the ceramic surface to be filled with resin composite. After filling the tubes, the resin cylinders were light-cured for 40 seconds (Demetron, LC Kerr Corporation, Orange, CA, USA) with the light source placed at the upper end of the cylinders, thus light-curing all of them simultaneously. The light-curing equipment was set at $499 \mathrm{~mW} / \mathrm{cm}^{2}$ (from $491 \mathrm{~mW} / \mathrm{cm}^{2}$ to $507 \mathrm{~mW} / \mathrm{cm}^{2}$ ) with the aid of a radiometer (Radiômetro Digital,

Table 1- Mean and standard deviation for bond strength (MPa) for the different ceramic surface treatments $(p=0.3197)$

\begin{tabular}{ccc}
\hline Treatment & Mean & Standard Deviation \\
\hline C & $16.72^{\mathrm{A}}$ & 6.72 \\
S & $20.34^{\mathrm{A}}$ & 5.6 \\
US & $18.63^{\mathrm{A}}$ & 3.84 \\
F & $16.99^{\mathrm{A}}$ & 6.53 \\
F+US & $14.80^{\mathrm{A}}$ & 3.11 \\
\hline
\end{tabular}

Mean followed by same letter indicates no significant difference 
NewDent, Ribeirão Preto, SP, Brazil) and reviewed after every five light-curing cycles. Immediately after light-curing, the silicone tubes were cut using a scalpel blade 12 and disposed of in order to obtain $4 \mathrm{~mm}$ high $\times 0.8 \mathrm{~mm}$ diameter composite resin cylinders bonded to the ceramic surface, with a bonding area of $0.5 \mathrm{~mm}^{2}$. The specimens were stored in a bacteriological incubator (ECB 1.3 digital, Odontobrás Ind. e Com. Equip. Med. Odont. Ltda, Ribeirão Preto, SP, Brazil) at $37^{\circ} \mathrm{C}$ for 24 hours until the bond strength tests were performed.

The ceramic discs were fixed to a device attached to the universal testing machine (DL2000, EMIC Ind e Com Ltda, São José dos Pinhais, PR, Brazil). The composite resin cylinders were aligned to a loading cell of $20 \mathrm{KgF}$. A $0.3 \mathrm{~mm}$ diameter stainless steel wire looped around both the extremity of the loading cell and the composite resin cylinder, simultaneously. The wire maintained contact with the inferior semicircle of the cylinders, as close as possible to the area bonded to the ceramic. The test was carried out at a speed of $0.5 \mathrm{~mm} / \mathrm{min}$, until bonding failure, for each cylinder sequentially, that is, one at a time.

Table 2- Failure mode for the different ceramic surface treatments

\begin{tabular}{cccccccccccc}
\hline Failure mode & \multicolumn{2}{c}{$\mathbf{C}$} & \multicolumn{2}{c}{$\mathbf{S}$} & \multicolumn{2}{c}{ US } & \multicolumn{2}{c}{$\mathbf{F}$} & \multicolumn{2}{c}{ F+US } \\
\hline Resin Cohesion & $\mathbf{n}$ & $\%$ & $\mathbf{n}$ & $\%$ & $\mathbf{n}$ & $\%$ & $\mathbf{n}$ & $\%$ & $\mathbf{n}$ & $\%$ \\
Adhesive & 25 & 62.5 & 24 & 60 & 24 & 60 & 28 & 70 & 21 & 52.5 \\
Mixed & 8 & 20 & 8 & 20 & 8 & 20 & 2 & 5 & 12 & 30 \\
Ceramic cohesion & 2 & 5 & 4 & 10 & 2 & 5 & 1 & 2.5 & 1 & 2.5 \\
Failure before testing & 1 & 2.5 & 3 & 7.5 & 0 & 0 & 3 & 7.5 & 2 & 5 \\
Total & 4 & 10 & 1 & 2.5 & 6 & 15 & 6 & 15 & 4 & 10 \\
\hline
\end{tabular}

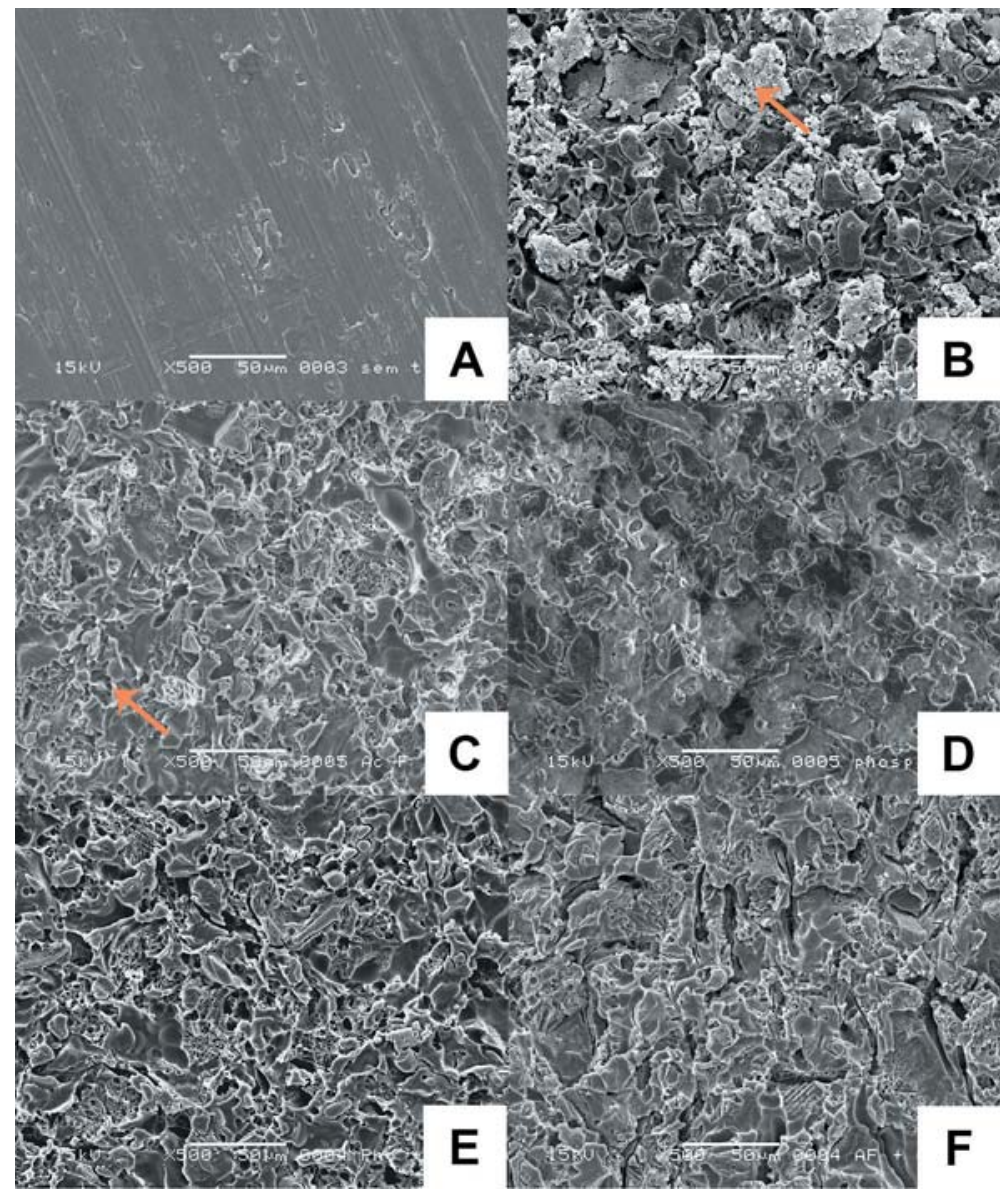

Figure 1- Photomicrographs of the ceramic surfaces as seen using a scanning electron microscope (SEM) at 500X magnification. A - Unetched ceramic surface; B - Ceramic surface of Group C; C - Ceramic surface of Group S; D Ceramic surface of Group F; E - Ceramic surface of Group US; F - Ceramic surface of Group F+US. The arrows show residues left following cleaning 
The failure mode was assessed using a stereoscopic lens (EK3ST Model, Eikonal, São Paulo, São Paulo, Brazil) at 20X magnification. The failure modes were classified as adhesive failure, ceramic or resin cohesion failure, or mixed. Cohesion failure was defined as a fracture in the body of the ceramic or the resin, adhesive failure when there was a fault at the junction between the ceramic and the resin, and mixed when there was both adhesive and cohesion failure, simultaneously.

\section{Micromorphological analysis}

One of the six ceramic discs used to evaluate surface micromorphology did not receive any surface treatment, including hydrofluoric acid. The five remaining discs underwent surface treatment after hydrofluoric acid etching.

The specimens were then stored in an incubator at $50^{\circ} \mathrm{C}$ for 3 hours to remove any water particles, 24 hours prior to SEM assessment. The samples were then placed in airtight glass jars containing silica gel and sealed to ensure moisture elimination.

The specimens received a layer of gold/ palladium. The discs were positioned in the SEM
(JSM 5600LV, JEOL, Tokyo, Japan) and images were obtained at 500X and 2,500X magnification.

\section{Statistical analysis}

For each ceramic disc, the mean micro-shear bond strength value for the resin cylinders was considered. After exploratory analysis, the data were tested using one-way analysis of variance $(p<0.05)$ on SAS statistical software (Release 9.2, 2008, Institute Inc., Cary, NC, USA). Descriptive analysis was used for surface micromorphology and failure mode.

\section{RESULTS}

Table 1 describes the mean values of microshear bond strength and shows no significant difference between the surface treatment methods $(p=0.3197)$. Table 2 shows the frequency of failure modes following micro-shear bond strength testing. The most frequent failure modes were resin cohesion followed by adhesive failure.

When inspecting the SEM images, the ceramic surface that received no treatment appeared

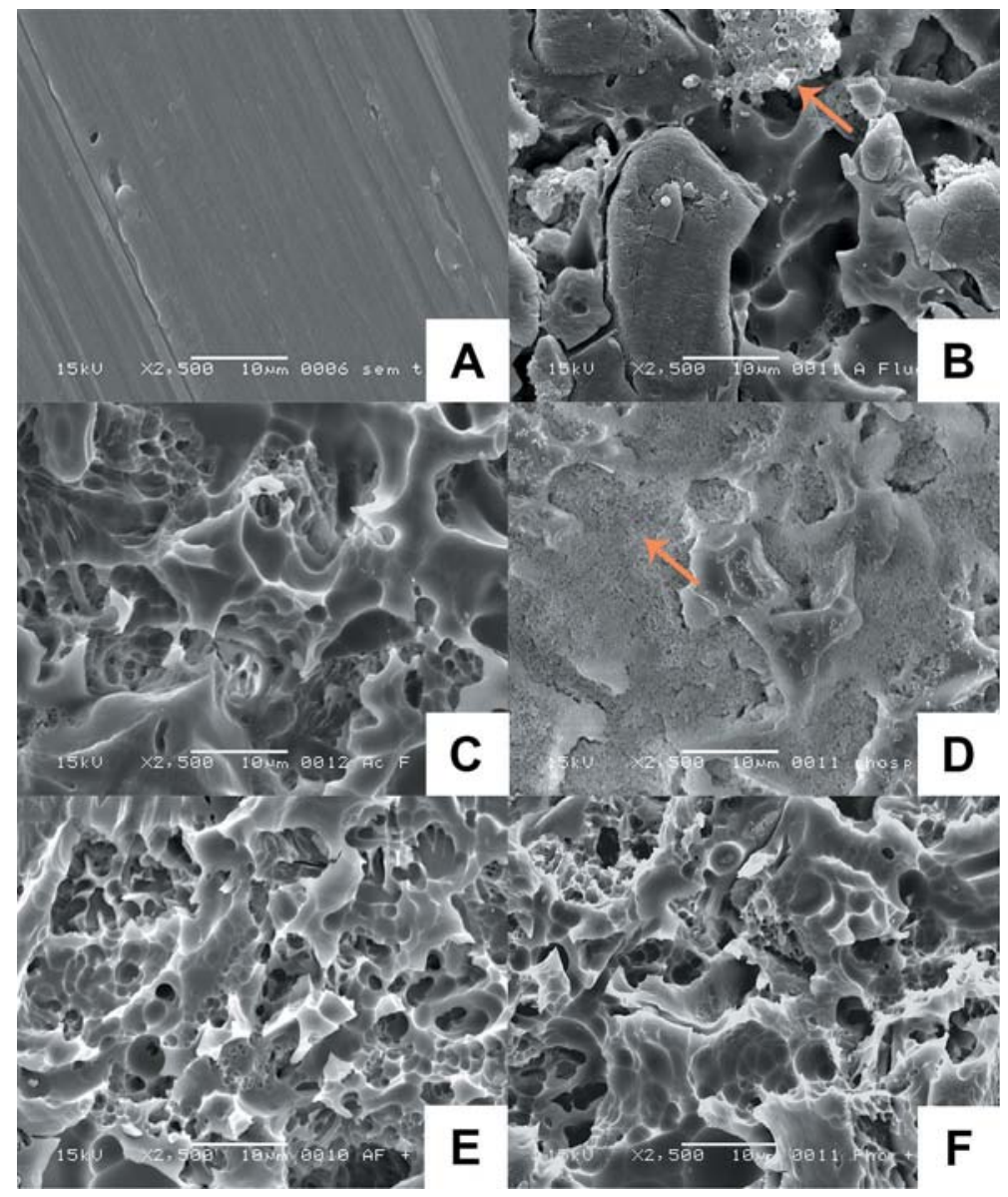

Figure 2- Photomicrographs of the ceramic surfaces as seen using a scanning electron microscope (SEM) at 2,500X magnification. A - Unetched ceramic surface; B - Ceramic surface of Group C; C - Ceramic surface of Group S; D Ceramic surface of Group F; E - Ceramic surface of Group US; F - Ceramic surface of Group F+US. The arrows show residues left following cleaning 
smooth without porosity, as a result of the polish obtained when the ceramic disc was prepared (Figure 1A). Regarding the control group (C) and the spray group (S), which had the hydrofluoric acid rinsed with water and water-air spray, respectively, irregular micrometric structures were observed, which probably consisted of products from the acid etch step (Figures $1 \mathrm{~B}$ and $1 \mathrm{C}$ ). Such structures were not encountered on the surfaces of the other groups. Regarding groups US, F and F+US, no significant difference was observed in terms of surface micromorphology (Figures 1D, 1E and 1F).

At higher magnification (2,500X), Groups US and $\mathrm{F}+\mathrm{US}$ (Figures $2 \mathrm{E}$ and $2 \mathrm{~F}$ ) showed no debris or acid etch residue, whereas, in the two groups in which no ultrasound was used, some debris were still present. This suggests that ultrasonic cleaning was more efficient. A curious observation was noticed when the phosphoric acid smear was used. At lower magnification, some darkened areas were observed, which could have been remains of the phosphoric acid itself, which was not completely removed under running water only. At higher magnification, it is obvious that this surface is different from the other groups. It shows a granular or sandy aspect. It is likely that some form of over-etching may have occurred on the ceramic surface, when phosphoric acid was applied. As no ultrasonic treatment was used in this group, the products from over-etching were not efficiently removed.

\section{DISCUSSION}

Resin cements and internal ceramic surface treatment are used to promote bonding between ceramic surface and tooth ${ }^{7,10}$. Such treatments are necessary to modify the surface of these structures, because they are usually smooth and with low surface energy, which prevents the penetration of the bonding agents that create satisfactory chemical or micromechanical retention ${ }^{20}$.

Dental ceramics have a crystalline microstructure containing large amounts of loose crystals or granules, which form their microtopography? Feldspathic ceramic is composed of feldspath $(65 \%)$, quartz $( \pm 25 \%)$ and metal oxides $( \pm 10 \%)$. Sodium and alkaline earth oxides are added as bivalent glass modifiers to improve its translucent properties. Potassium oxide $\left(\mathrm{K}_{2} \mathrm{O}\right)$ is one of the main components of feldspathic ceramics, which is used to provide the material with a coefficient of thermal dilation as similar as possible to the metal alloys used in metal-ceramic restorations ${ }^{4}$. The large quantity of glass matrix optimizes the materials vulnerability to acid etching, which allows the formation of microporosities that improve adhesion $^{12}$. Aluminium oxide sandblasting and hydrofluoric acid etching promote an increase of ceramic surface area, creating an irregular topography and increasing surface energy for micromechanical retention of the resin cement ${ }^{13,24}$.

Hydrofluoric acid etching is widely used to pretreat feldspathic ceramic surfaces, because it acts selectively on the silica glass matrix, forming hexafluorosilicates, thus creating a porous surface to facilitate micromechanical interlocking with the resin cement $5,12,23,24$. For feldspathic ceramics, surface etching with hydrofluoric acid was used at a concentration of $9 \%$ to $10 \%^{1,3,8,11,21}$, and the etching time ranged between one $\mathrm{e}^{3,9,15,23-25}$ and two minutes ${ }^{15,23}$. However, studies comparing etching times reported no difference among the times used, as long as the minimum etching time was one minute ${ }^{15,23}$.

Following etching of silica-based ceramics, it has been observed that hydrofluoric acid leads to the formation of insoluble byproducts, such as silica and fluoride salts, which may remain on the ceramic surface ${ }^{9}$. These particles may interfere with the bond strength between the ceramic and the substrate onto which it is cemented ${ }^{9,16,22}$. In the present study, the control groups SEM images (which only underwent etching with hydrofluoric acid), revealed large quantities of residues when compared to the untreated ceramic and to the groups that received some form of surface cleaning. However, Phark, et al. ${ }^{17}$ (2009) reported that shear bond strength is not affected by contamination or cleaning procedures, as shown in this study.

In order to remove byproducts following hydrofluoric acid etching, some authors used ultrasonic washing $3,6,15,17,24,37 \%$ phosphoric acid smear ${ }^{19}$, rinsing with running water ${ }^{12,14,23}$, or a combination of $37 \%$ phosphoric acid smear and ultrasonic washing ${ }^{13}$. The present study demonstrated no significant difference in bond strength using different methods of ceramic surface cleaning, despite the presence of byproducts observed by SEM following surface cleaning with water spray, unlike in groups US and F+US, in which ultrasonic bath was used. At 2,500X magnification, ultrasonic washing improved the removal of debris, when compared with the group in which phosphoric acid was used, where residue was observed after rinsing under running water. However, the longterm effect of this interference has not yet been evaluated.

In this study, the main failure mode was resin cohesion followed by adhesive failure, thus showing that the hydrofluoric acid residue did not affect bond strength. Phark, et al. ${ }^{17}$ (2009) also observed no influence on bond strength from the contaminants left by the etching agent on the ceramic surface. In addition, Fabianelli, et al. ${ }^{9}$ (2010) demonstrated that the silane application technique is more important than hydrofluoric acid etching. Other studies also 
have shown increase in bond strength following silane application, regardless of the surface etching technique $3,17,23,24$. Therefore, the residue does not seem to interfere with bond strength, as shown in this study.

Regardless of the cleaning technique used on the ceramic surface, the presence or absence of residue following hydrofluoric acid etching did not influence the bond strength between ceramic and resin. The post-hydrofluoric acid etching cleaning method may simply consist of spraying with water for 90 seconds.

\section{CONCLUSION}

The micro-shear bond strength between the feldspathic ceramic and adhesive system was not influenced by different ceramic cleaning techniques, following hydrofluoric acid etching. Micromorphological evaluation of the ceramic surface revealed little to no residue following hydrofluoric acid etching, when combined with ultrasonic washing.

\section{ACKNOWLEDGEMENTS}

To Piracicaba Dental School (UNICAMP) for the use of the SEM to capture images.

\section{REFERENCES}

1- Attia A, Lehmann F, Kern M. Influence of surface conditioning and cleaning methods on resin bonding to zirconia ceramic. Dent Mater. 2011;27:207-13.

2- Blatz MB, Sadan A, Kern M. Resin-ceramic bonding: a review of the literature. J Prosthet Dent. 2003;89:268-74.

3- Brentel AS, Özcan M, Valandro LF, Alarça LG, Amaral R, Bottino MA. Microtensile bond strength of a resin cement to feldspathic ceramic after different etching and silanization regimens in dry and aged conditions. Dent Mater. 2007;23:1323-31.

4- Cesar PF, Yoshimura HN, Miranda Júnior WG, Okada CY. Correlation between fracture toughness and leucite content in dental porcelains. J Dent. 2005;33:721-9.

5- Dalkiz M, Sipahi C, Beydemir B. Effects of six surface treatment methods on the surface roughness of a low-fusing and an ultra-low-fusing feldspathic ceramic material. J Prosthodont. 2009;18:217-22.

6- Dündar M, Özcan M, Gökçe B, Çömlekoğlu E, Leite F, Valandro LF. Comparison of two bond strength testing methodologies for bilayered all-ceramics. Dental Mater. 2007;23:630-6.

7- El Zohairy AA, Saber MH, Abdalla AI, Feilzer AJ. Efficacy of microtensile versus microshear bond testing for evaluation of bond strength of dental adhesive systems to enamel. Dent Mater. 2010;26:848-54.
8- Ersu B, Yuzugullu B, Yazici AR, Canay S. Surface roughness and bond strengths of glass-infiltrated alumina-ceramics prepared using various surface treatments. J Dent. 2009;37:848-56.

9- Fabianelli A, Pollington S, Papacchini F, Goracci C, Cantoro $A$, Ferrari $M$, et al. The effect of different surface treatments on bond strength between leucite reinforced feldspathic ceramic and composite resin. J Dent. 2010;38:39-43.

10- Frankenberger R, Reinelt C, Petschelt A, Krämer N. Operator vs. material influence on clinical outcome of bonded ceramic inlays. Dent Mater. 2009;25:960-8.

11- Hooshmand T, Parvizi S, Keshvad A. Effect of surface acid etching on the biaxial flexural strength of two hot-pressed glass ceramics. J Prosthodont. 2008;17:415-9.

12- Kukiattrakoon B, Thammasitboon K. Optimal acidulated phosphate fluoride gel etching time for surface treatment of feldspathic porcelain: on shear bond strength to resin composite. Eur J Dent. 2012;6:63-9.

13- Magne $P$, Cascione D. Influence of post-etching cleaning and connecting porcelain on the microtensile bond strength of composite resin to feldspathic porcelain. J Prosthet Dent. 2006;96:354-61.

14- Melo RM, Valandro L, Bottino MA. Microtensile bond strength of a repair composite to leucite-reinforced feldspathic ceramic. Braz Dent J. 2007;18:314-9.

15- Menezes FC, Borges GA, Valentino TA, Oliveira MA, Turssi CP, Correr-Sobrinho $L$. Effect of surface treatment and storage on the bond strength of different ceramic systems. Braz J Oral Sci. 2009;8:119-23.

16- Monticelli F, Toledano M, Osorio R, Ferrari M. Effect of temperature on the silane coupling agents when bonding core resin to quartz fiber posts. Dent Mater. 2006;22:1024-8.

17- Phark JH, Duarte S Jr, Kahn H, Blatz MB, Sadan A. Influence of contamination and cleaning on bond strength to modified zirconia. Dent Mater. 2009;25:1541-50.

18- Pollington S, Fabianelli A, Noort RV. Microtensile bond strength of a resin cement to a novel fluorcanasite glass-ceramic following different surface treatments. Dent Mater. 2010;26:864-72.

19- Quaas AC, Yang B, Kern M. Panavia F 2.0 bonding to contaminated zirconia ceramic after different cleaning procedures. Dent Mater. 2007;23:506-12.

20- Queiroz JR, Benetti P, Özcan M, Oliveira LF, Della Bona A, Takahashi FE, et al. Surface characterization of feldspathic ceramic using ATR FT-IR and ellipsometry after various silanization protocols. Dent Mater. 2012;28:189-96.

21- Saraç S, Elekdaq-Turk S, Saraç D, Turk T. Surface conditioning methods and polishing techniques effect on surface roughness of a feldspar ceramic. Angle Orthod. 2007;77:723-8.

22- Shimada Y, Yamaguchi S, Tagami J. Micro-shear bond strength of dual-cured resin cement to glass ceramics. Dent Mater. 2002;18:380-8.

23- Trakyali G, Malkondu O, Kazazoğlu E, Arun T. Effects of different silanes and acid concentrations on bond strength of brackets to porcelain surfaces. Eur J Orthod. 2009;31:402-6.

24- Yadav S, Upadhyay M, Borges GA, Roberts WE. Influence of ceramic (feldspathic) surface treatments on the micro-shear bond strength of composite resin. Angle Orthod. 2010;80:765-70. 25- Yi Y, Kelly JR. Failure responses of a dental porcelain having three surface treatments under three stressing conditions. Dent Mater. $2011 ; 27: 1252-8$. 